\title{
Desenvolvimento profissional docente numa licenciatura: interlocuções sobre o projeto integrador
}

\author{
ADÃO CARON CAMBRAIA
}

Instituto Federal de Educação, Ciência e Tecnologia Farroupilha, Santo Augusto, RS, Brasil

LENIR BASSO ZANON

Universidade Regional do Noroeste do Estado do Rio Grande do Sul, ljuí, RS, Brasil

\section{RESUMO}

Este texto tem como objetivo entender as características que limitam e/ou favorecem o Desenvolvimento Profissional do Docente (DPD) por meio do planejamento, do desenvolvimento e da avaliação do Projeto Integrador (PI). Para essa análise, criamos, no curso de Licenciatura em Computação (LC) do Instituto Federal Farroupilha - Campus Santo Augusto, um grupo de estudo coletivo, denominado Desenvolvimento Profissional Docente na Licenciatura em Computação (DPDLiC), que teve como base teórica a pesquisa-ação. Os encontros foram organizados de forma presencial e no ciberespaço, com vistas a proporcionar uma participação ativa dos professores. O estudo possibilitou entender e reforçar a concepção de que os próprios professores/formadores, ao organizar colaborativamente o PI, responsabilizam-se pela formação de seus pares e favorecem o DPD.

\section{PALAVRAS-CHAVE}

desenvolvimento profissional docente; pesquisa-ação; projeto integrador. 


\title{
PROFESSIONAL TEACHER DEVELOPMENT IN A TEACHING DEGREE: IDEAS ON AN INTEGRATIVE PROJECT
}

\begin{abstract} of their peers, and they favor PTD.

KEYWORDS

professional development; action research; integrative project.
\end{abstract}

This text aims to understand the characteristics that limit and/or benefit Professional Teacher Development (PTD) through the planning, development and evaluation of an Integrative Project (IP). For this analysis, we created a collective study group, called Professional Development in Teaching Computing (Desenvolvimento Profissional Docente na Licenciatura em Computação - DPDLiC), in the Computing Department of the Farroupilha Federal Institute - Campus Santo Augusto. The study group had a critical and emancipatory Action Research approach as its theoretical base. The meetings were organized in person and in cyberspace, in order to allow for teachers' active participation. The study made it possible to understand and reinforce the idea that the teachers/trainers themselves, when organizing the IP collaboratively, take responsibility for the training

\section{DESARROLLO PROFESIONAL DOCENTE EN UNA LICENCIATURA: INTERLOCUCIONES SOBRE EL PROYECTO INTEGRADOR}

\section{RESUMEN}

Este texto tiene como objetivo entender las características que limitan y/o favorecen el Desarrollo Profesional del Docente (DPD) por medio de la planificación, desarrollo y evaluación del Proyecto Integrador (PI). Para este análisis, creamos, en el curso de Licenciatura en Computación del Instituto Federal Farroupilha-Campus Santo Augusto, un grupo de estudio colectivo, denominado Desarrollo Profesional Docente en la Licenciatura en Computación (DPDLiC), que tuvo como base teórica la investigación-acción. Los encuentros se organizaron de forma presencial y en el ciberespacio, con miras a proporcionar una participación de los profesores. El estudio posibilitó entender y reforzar la concepción de que los propios profesores/formadores, al organizar colaborativamente el PI, se responsabilizan por la formación de sus pares y favorecen el DPD.

PALABRAS CLAVE

desarrollo profesional docente; investigación-acción; proyecto integrador. 
Este texto faz parte de uma investigação de maior abrangência, que partiu de uma revisão de estudos sobre o Desenvolvimento Profissional Docente - DPD (Cambraia e Zanon, 2016), elaborada com vistas a situar e justificar a importância da discussão fundamentada dessa temática no contexto da Licenciatura em Computação (LC). O presente texto trata de um processo de Desenvolvimento Profissional Docente na Licenciatura em Computação (DPDLiC) coletivamente construído.

Geralmente, cursos de formação docente carregam indícios de que possuem heranças de um modelo calcado na racionalidade técnica (Libâneo, 2015; Schnetzler, 2000). A partir desse modelo de formação, acreditou-se que os professores estariam instrumentalizados para resolver os problemas que surgem no exercício profissional. Mas, resultante desse processo, ocorre uma desarticulação na formação docente e emergem: a) descompassos entre a formação pedagógica e a formação nos conteúdos do ensino que ministrarão (computação), resultando numa formação demasiadamente genérica (Libâneo, 2015); e b) descompassos entre conhecimentos teóricos e o mundo da prática profissional em que atuarão os futuros professores. Nesse contexto, argumentamos em defesa do DPDLiC para avançarmos no entendimento sobre indícios de como provocar rupturas com esses descompassos.

No DPDLiC foram coletivamente planejados e realizados encontros sistemáticos do grupo responsável pelo estudo, de forma presencial e no ciberespaço, sendo este criado especificamente para possibilitar as interações a distância. Nos encontros presenciais eram tematizadas questões e abordagens compreensivas sobre diferentes aspectos do processo formativo, contando com interações permanentemente alimentadas pela postagem de distintos tipos de materiais no ciberespaço ${ }^{1}$. Esses encontros foram gravados em áudio e transcritos, produzindo parte dos dados da pesquisa. No ciberespaço (ferramenta fórum) foram realizadas discussões, reflexões por meio do exercício da escrita sobre as Práticas do Ensino da Computação $(\mathrm{PEC})^{2}$. Para apresentação e análise dos dados selecionamos episódios, que possibilitaram discutir indícios de um DPD na medida em que o grupo passava a interagir significativamente.

Para a análise dos episódios, utilizamos a abordagem microgenética (GÓES, 2000), que, de um modo geral, pode ser referida como:

[...] uma forma de construção de dados que requer a atenção a detalhes e o recorte de episódios interativos, sendo o exame orientado para o funcionamento dos sujeitos focais, as relações intersubjetivas e as condições sociais da situação, resultando num relato minucioso dos acontecimentos. (GÓES, 2000, p. 9)

A análise dos episódios foi desenvolvida no intuito de permitir entender como ocorre o DPD com recriação da prática curricular. Para isso, a investigação rea-

1 Para mais informações sobre a organização desse processo formativo, ver Cambraia e Bender (2015).

2 No IFFAR usamos a sigla PeCC para Prática enquanto Componente Curricular. Como o texto aborda a problemática da LC, usarei Prática do Ensino da Computação (PEC), que é a denominação dada na LC para o Componente Curricular Articulador. 
lizada é caracterizada como um estudo de caso (Lüdke e André, 1986). O processo investigativo foi organizado e desenvolvido com uma modalidade de pesquisa-ação crítica e emancipatória (Carr e Kemmis, 1988) com vistas a promover melhorias na Licenciatura em Computação (LC). O grupo é formado principalmente por professores da LC, com participação assídua de 9 docentes ( 6 do campo da computação e 3 da pedagogia), além de dois alunos, um deles como bolsista de iniciação científica. Docentes de outros cursos participam esporadicamente.

Analisaremos um processo de planejamento, desenvolvimento e avaliação do Projeto Integrador (PI) e Seminário Integrador (SI) realizado na PEC do $3^{\circ}$ semestre da LC do Instituto Federal de Educação, Ciência e Tecnologia Farroupilha (IFFAR), Campus Santo Augusto. No início de cada semestre, prevemos, no Projeto Pedagógico, o planejamento de um PI. Geralmente, o coordenador do curso indica dois professores (um da área técnica e outro da área pedagógica) para articularem as ações com os demais professores.

Trata-se da análise de uma interlocução realizada entre os professores no DPDLiC.É um convite à reflexão crítica de forma a proporcionar o planejamento e desenvolvimento colaborativo do PI. Os fatores que nos levaram a analisar o projeto realizado devem-se à construção coletiva de um relato de experiência organizado por dois professores ${ }^{3}$ e um aluno do curso, intitulado O projeto integrador num curso de Licenciatura: a reconstrução de saberes por meio do movimento dialógico, publicado em Hames, Zanon e Pansera-de-Araújo (2016) ${ }^{4}$. Então, utilizamos esse relato de experiência e os encontros de planejamento/discussão/avaliação para construir argumentos que nos conduzem à defesa de entendimentos sobre o DPDLiC.

Para preservar o anonimato dos sujeitos e expor com transparência a análise das transcrições e todas as informações, sem constranger os envolvidos na pesquisa, utilizamos para cada professor um nome fictício. Os trechos selecionados do relato de experiência publicado em livro estão em itálico, para diferenciar das demais citações de autores, e os episódios estão identificados como selecionados no ciberespaço ou presencial, para construir um entendimento sobre a interação no DPDLiC.

Os próximos tópicos demonstram tal processo interativo vivenciado no DPDLiC: no primeiro, o planejamento do projeto; no segundo, as ações em interação no desenvolvimento do PI e realização do SI; e, no terceiro, uma avaliação do processo desenvolvido no $3^{\circ}$ semestre da LC.

3 Um dos professores é autor deste texto. A escolha desse semestre para análise também ocorreu pelo fato de que não participei da execução do projeto em sala de aula - o que permitiu um olhar de fora. O DPDLiC proporcionou-me a participação no planejamento e acompanhamento da PEC, demonstrando a importância desse espaço para que mais professores participem desse processo de forma ativa. Uma evidência disso é a construção coletiva do relato reflexivo envolvendo um professor da área pedagógica (coordenador da PEC), um professor da área específica da computação (autor deste texto) e um aluno da LC. Todos membros participantes do DPDLiC.

4 Embora a publicação do relato de experiência tenha ocorrido em 2016, a experiência é de 2014. 


\section{PLANEJAMENTO COLABORATIVO NO CONTEXTO DO PROJETO INTEGRADOR}

No início de cada semestre está previsto no Projeto Pedagógico do Curso (PPC) o planejamento de um projeto. Sempre tomamos o cuidado para que diferentes professores coordenem, pois exige-se um processo participativo intenso para a sua realização. Como cada semestre tem diferentes temáticas, cada turma demanda um processo de planejamento, desenvolvimento, acompanhamento e avaliação, que deve ser adaptado a cada realidade. Por isso, criamos fóruns de discussão no ciberespaço para cada um dos projetos, com o intuito de construir "uma compreensão do caso que seja simultaneamente uma construção do que se pretende, e não só do que se deve fazer” (Contreras, 2012,p.121), permitindo maior liberdade na recriação da prática curricular. Assim, a autonomia que os professores possuem para "tomar decisões de índole curricular determina em grande medida o desenvolvimento profissional que pode ocorrer ao se levar a cabo uma proposta curricular" (Stenhouse, 1984 apud García, 1999, p. 142).

Trata-se de refletir criticamente sobre o processo de recriação da prática curricular desencadeado.

A reflexão crítica é libertadora porque nos emancipa das visões acríticas, dos pressupostos, hábitos, tradições e costumes não questionados e das formas de coerção e de dominação que tais práticas supõem e que muitas vezes nós mesmos sustentamos, em um engano. (Contreras, 2012, p. 181)

Para isso, no início do relato de experiência analisado neste texto fizemos um estudo de documentos que permitem um esclarecimento do que seja a PEC (estudo realizado com a disponibilização de texto no ciberespaço) e, a partir disso, identificamos a necessidade de "acompanhar e sistematizar a PEC, compartilhar o projeto interdisciplinar e potencializar discussöes/relatos, propomos a criação de espaços interativos" (Cambraia, Benvenutti e Moraes, 2016, p. 201), o DPDLiC. Demonstramos a conscientização dos docentes sobre a necessidade de interlocuções para o desenvolvimento curricular e, consequentemente, o DPD, pois

o trabalho docente se faz com o auxílio do outro, constituindo um olhar integral sobre a construção do conhecimento, de forma que os professores se percebam em (re)construção diante das experiências vividas em sua profissão. (Cambraia, Benvenutti e Moraes, 2016, p. 202)

Assim, constituímos um coletivo organizado numa pesquisa-ação crítica e emancipatória (Carr e Kemmis, 1988). Sendo que a formação de professores "passa pela condição de que esses vão assumindo uma identidade docente, o que supõe a assunção do fato de serem sujeitos da formação e não objetos dela" (Imbernón, 2010, p. 11).

Para desenvolver o projeto do $3^{\circ}$ semestre, a temática proposta foi "políticas públicas voltadas ao desenvolvimento de uma inclusão digital na educação". O encontro para planejamento foi conduzido por um dos professores/coordenador da 
PEC, que iniciou as discussões com o intuito de construir um projeto: "Como será o trabalho neste semestre? Minha disciplina tem tudo a ver com essa temática, pois é Gestão, está envolvida com esses problemas" (Marta, $1^{\circ}$ encontro presencial, 19 de fevereiro de 2014, p. 7). A professora demonstra, dessa forma, o interesse em dialogar com os colegas sobre o planejamento do projeto.

Já uma professora do Núcleo Específico da Computação, ao sentir dificuldade em se inserir na proposta, ressaltou que "gostaria de ouvir e saber se os outros da área mais técnica conseguem se envolver" (Jussara, $1^{\circ}$ encontro presencial, 19 de fevereiro de 2014, p. 7), transparecendo indignação em sua fala. Essa manifestação pode ser entendida como certo movimento de resistência em participar ativamente num processo de estudo e planejamento colaborativo ${ }^{5}$, pois é necessário tempo, empenho, exposição de crenças e abertura para lidar com situações de conflito e dificuldade, como no caso do desenvolvimento do PI.

Por um lado, conforme Bazzo (2011), essa resistência ocorre devido a uma "cobrança” para que o professor trabalhe conteúdos de aplicação imediata ao mercado de trabalho para ser considerado um bom professor. Dessa forma, "veste a roupa" do profissional que atua no mercado ao satisfazer o desejo imediato dos alunos, instrumentalizando-os com aplicações de "última geração", mas refutando reflexões críticas sobre a profissão e concebendo sua disciplina como autossuficiente, negligenciando a interação com as outras disciplinas do curso.

Por outro, essa resistência pode ser atribuída ao descompasso entre conhecimentos de computação e de pedagogia, como já tratado neste texto, entre conhecimentos humanísticos e tecnológicos, como referido por Cafezeiro, Costa e Kubrusly (2016). Por vezes, o docente, devido à sua história de formação e à sua atuação profissional no campo das ciências exatas, concebe a ciência e os conhecimentos científicos de forma tecnicista e positivista, sem abertura para participar de processos interativos pautados na reflexão crítica sobre as relações entre teorias e práticas (Carr e Kemmis, 1988). Nessa condição, o docente, principalmente aquele que atua em disciplinas de formação técnica, permanece fechado e limitado aos "muros" do conteúdo disciplinar.

Essa concepção e essa postura do docente, além de desfavorecer o avanço dos processos interativos desenvolvidos na direção de planejar e realizar mudanças coletivas no curso com vistas a promover melhorias na formação inicial, prejudicam diretamente a aprendizagem e a formação dos futuros professores, potencializando a evasão, a retenção e as dificuldades de aprendizagem, pelos estudantes.

5 Essa resistência também é relatada no texto "Currículo Integrado na Educação Profissional de Nível Médio: o Curso Técnico em Agropecuária no Instituto Federal Farroupilha". Os autores afirmam em relato: "há fortes resistências dos educadores quando se expõe a necessidade de romper com as formas tradicionais de distribuição das disciplinas e dos respectivos conteúdos. O currículo formal já é parte constitutiva de certa cultura escolar. Além da fragmentação por disciplinas e a organização de planos de ensino correspondentes a essa fragmentação, outros aspectos não menos importantes dificultam a tentativa de ruptura e permanecem como entraves ao processo de ensino e aprendizagem" (Lottermann, Hames e Rosmann, 2016, p. 97). 
[...] Arriscamos dizer que o baixo desempenho nas disciplinas ditas "ciências exatas" nasce no conflito entre a expectativa por um conhecimento híbrido e problematizador e o defrontamento com um conhecimento que se pretende puramente técnico. Este conflito é desmotivador, uma vez que não conduz à compreensão da utilidade destes conhecimentos na profissão. (Cafezeiro, Costa e Kubrusly, 2016, p. 2247)

$\mathrm{Na}$ tentativa de superar a resistência e contribuir com algumas possibilidades de articulação, o professor Gilmar exemplifica o que entende quando pensa na temática para o semestre: "São políticas públicas que se relacionam com a educação e computação. Quem sabe poderíamos especificar políticas públicas de inclusão digital? Se a gente pesquisar vai ver que tem uma infinidade. É o PROINFO, o UCA, é o Telecentro, etc" (Gilmar, $1^{\circ}$ encontro presencial, 19 de fevereiro de 2014, p. 7), fazendo uma mediação para ampliar o leque de abrangência do projeto e possibilitar que mais professores se envolvam nessa construção.

Mas "precisamos focar no sistema de ensino [...] focar na necessidade de cada município, de cada estado" (Marta, $1^{\circ}$ encontro presencial, 19 de fevereiro de 2014, p. 7); e complementa: "Tenho trabalhado em minha disciplina com o Guia de Tecnologias Educacionais", demonstrando com isso que possui uma ideia para o projeto e que também está tentando envolver os demais professores nessa proposta.

A dificuldade em articular professores do Núcleo Específico da Computação com professores do Núcleo Comum também é percebida no excerto da professora Jussara. "Na minha disciplina, que é mais técnica, tenho dificuldade em entender, como é que me enxergo diante das políticas públicas [temática do $3^{\circ}$ semestre]. Penso que se for trabalhar a minha disciplina vai fugir da temática, que é políticas públicas" (Jussara, $1^{\circ}$ encontro presencial, 19 de fevereiro de 2014, p. 8); e o professor Pedro reforça: "É como programação, tem algumas coisas difíceis de relacionar, são temas bem pedagógicos, como as políticas públicas" (Pedro, $1^{\circ}$ encontro presencial, 19 de fevereiro de 2014, p. 8). O episódio demonstra que a segmentação entre conhecimento da computação e didático/pedagógico não é um fator presente apenas entre os alunos, também precisamos repensar nossas concepções no sentido de acabar com as dicotomias presentes em nossas cabeças. Ambos deixam transparecer a existência de uma divisão entre quem faz e quem pensa a educação. É importante destacar que não se trata de que professores de pedagogia saibam computação ou vice-versa, mas como todos são docentes, a pesquisa sobre o ensinar e aprender é comum a todos! De acordo com Shulman (1986), o conhecimento específico de cada campo é um pressuposto fundamental da profissão docente, porém também é necessário compreender o modo como esse conhecimento se transforma em ensino e isso exige uma permanente interlocução entre os sujeitos, contribuindo para minimizar a dicotomização teoria e prática.

Com o intuito de organizar o PI e percebendo que as discussões entravam num caminho de impossibilidade de articulação, o professor Gilmar retoma a discussão: "Pessoal, a professora Marta está trazendo ideias, mas ela não pode responder por todos. Vocês concordam? O que poderíamos fazer para dar mais algumas sugestões? Onde a professora Marta pode escrever essa ideia inicial e receber sugestões dos co- 
legas?"(Gilmar, $1^{\circ}$ encontro presencial, 19 de fevereiro de 2014,p. 7-8), e a professora Jussara, com uma certa irritação em sua fala, responde: "E esse grupo aí [ciberespaço], vamos escrever um documento ou algo assim" (Jussara, $1^{\circ}$ encontro presencial, 19 de fevereiro de 2014, p. 8), sendo rapidamente complementada pela professora Marta: "Mas tem que ser agora isso, precisamos escrever esse projeto, quem são os professores deste semestre? Estão apenas eu e a professora Jussara" (Marta, $1^{\circ}$ encontro presencial, 19 de fevereiro de 2014, p. 8); ou seja, não estavam presentes todos os professores do semestre. A professora Marta demonstra urgência na elaboração do projeto: "Tem que ser agora isso", pois tem a consciência de que se adiar pode ser tarde para colocar em prática e fazer os devidos ajustes, o que demonstra a importância do ciberespaço como forma de compartilhamento das informações produzidas pelo grupo para que os demais possam se inteirar do planejado e participar com sugestões, envolvendo-se e acompanhando as propostas pensadas no coletivo.

Com isso, a professora Marta iniciou o diálogo e expôs sua ideia:

Uma questão é a gestão educacional dentro da tecnologia, guias de tecnologias educacionais. Edital, o que ele tem? Tecnologia em 3D, por exemplo, quem e como foi criado esse programa. Isso não é de estrutura de dados? [...] Sempre foi um desafio para meus alunos, eles acessam o catálogo [Guia das Tecnologias Educacionais], mas se eles fossem convidados a participar? Qual o desafio para eles? Ler o edital, se candidatar a criar uma tecnologia? Já pensaram se a gente criasse uma tecnologia nas disciplinas técnicas [o professor fala o nome das disciplinas]? (Marta, $1^{\circ}$ encontro presencial, 19 de fevereiro de 2014, p. 8-9)

Ao dar essa explicação, a professora tenta articular sua disciplina com outras e os demais começam a interagir e elaborar possibilidades: "Mas, isso é um software educacional!" (Pedro, $1^{\circ}$ encontro presencial, 19 de fevereiro de 2014, p. 9). "Posso tentar contribuir estudando que tipos de dados são utilizados por essas tecnologias" (Jussara, $1^{\circ}$ encontro presencial, 19 de fevereiro de 2014, p. 9); e complementa: "Prefiro isso, pois é meu conteúdo, minha disciplina é extremamente teórica, assim, entender a estrutura dessas tecnologias, como são feitas, ficaria mais prática" (Jussara, $1^{\circ}$ encontro presencial, 19 de fevereiro de 2014, p. 9). Percebemos uma ruptura na resistência e os professores começam a interagir para planejar coletivamente, pois necessitamos de conteúdos conceituais de diferentes núcleos para compreender cada uma dessas temáticas definidas no PPC e investigadas. Dessa forma, demonstramos que é imprescindível uma modificação na forma de pensar e agir das pessoas envolvidas para uma concretização do PI. Concordamos com Morin de que promovemos reformas instrumentais não respondendo à necessidade da educação, a qual exige uma reforma do pensamento.

Os projetos de reforma giram em torno desse buraco negro que lhes é invisível. Só seria visível se as mentes fossem reformadas. E aqui chegamos a um impasse: não se pode reformar a instituição sem uma prévia reforma das mentes, mas não se podem reformar as mentes sem uma prévia reforma das instituições. (Morin, 2006, p. 99 , grifos do original) 
Ainda, para envolver mais colegas no projeto, o professor Gilmar complementa afirmando que "há as disciplinas de Informática na Educação e Sistemas Operacionais que fazem parte do semestre. Sistemas Operacionais é muito interessante discutir em Políticas Públicas, pois tem a questão do Software Livre; Informática na Educação tem tudo a ver com o projeto"(Gilmar, $1^{\circ}$ encontro presencial, 19 de fevereiro de 2014,p.11). E a professora Jussara complementa que "daqui a pouco isso vai ser a sementinha e, quando chegar na disciplina de Software Educacional, podemos criar algo" (Jussara, $1^{\circ}$ encontro presencial, 19 de fevereiro de 2014, p. 11). "Eu posso colocar isso no objetivo do projeto" (Marta, $1^{\circ}$ encontro presencial, 19 de fevereiro de 2014, p. 11). Diz o professor Gilmar: "ok, está aí o projeto do $3^{\circ}$ semestre. Vocês tinham que escrever isso" (Gilmar, $1^{\circ}$ encontro presencial, $19 \mathrm{de}$ fevereiro de 2014, p. 12).

O projeto foi escrito e disponibilizado no ciberespaço do DPDLiC. Em outros momentos esse projeto ficava de posse dos professores (que planejam o projeto) e com o setor ligado à Direção de Ensino, o que dificultava o diálogo no grupo como um todo. Mesmo sabendo que o setor passou a disponibilizar o projeto no site da instituição, não substitui o DPDLiC, pois não se trata apenas de disponibilizar a informação, mas também sentidos e significados que são criados na interlocução entre os sujeitos envolvidos na ação.

Basta iniciarmos uma ação, para que nos deparemos com algum tipo de "escape" de nossas intenções. A ação entra no "jogo das inter-retro-ações do meio em que intervém. [...] A ação não corre apenas o risco de fracasso, mas de desvio ou de perversão em seu sentido inicial" (Morin, 2011, p. 77). Por isso, a "estratégia deve prevalecer sobre o programa" (Morin, 2011, p. 78-79), pois o programa é fechado (obedece a uma sequência de comandos que devem ser executados sem variação). A estratégia, ao contrário, elabora um cenário de ação examinando as certezas e as incertezas da situação, e esse cenário pode e deve modificar-se segundo a informação recolhida. Ou seja, o acompanhamento desse processo por meio do DPDLiC é fundamental para modificarmos a tempo algumas ações planejadas.

Assim, nesse semestre propomos a socialização do projeto no DPDLiC para que os demais professores pudessem sugerir, acessar, ler e interferir em seu planejamento, acompanhamento e desenvolvimento. Sobre o ciberespaço, em relato posterior ao desenvolvimento do projeto, destacamos que: "O projeto integrador, disponibilizado no ambiente virtual facilitou $a$ construção de uma reflexão sobre o processo de integração curricular no curso de LC" (Cambraia, Benvenutti e Moraes, 2016, p. 202, grifos nossos), caracterizando o DPDLiC como um espaço que proporciona processos comunicacionais contextualizados e mais significativos para o DPD, pois:

[...] comunicar não é de modo algum transmitir uma mensagem ou receber uma mensagem. Isso é a condição física da comunicação, mas não é a comunicação. É certo que para comunicar é preciso enviar mensagens, mas enviar mensagens não é comunicar. Comunicar é partilhar o sentido. E isso já é mais difícil [...]. Já que isso quer dizer partilhar um contexto comum, partilhar uma cultura, partilhar uma história, partilhar uma experiência etc., é preciso já ter alguma coisa em comum para poder se comunicar. (Lévy, 1999, p. 147) 
Então, mais do que quantidades de mensagens trocadas, o DPDLiC proporcionou a socialização de sentidos e significados, o que permitiu concretizar as práticas profissionais e transformar os sujeitos a partir de uma ação formativa, possibilitando um DPD. Sem essa interação significativa na docência não concretizamos o PI. Assim, o DPD nos remete também ao "processo ou movimento de transformação dos sujeitos dentro de um campo profissional específico. Um processo, portanto, de vir a ser, de transformar-se ao longo do tempo ou a partir de uma ação formativa" (Fiorentini e Crecci, 2013, p. 13). No próximo tópico, analisamos o processo de desenvolvimento do PI.

\section{AÇÕES EM INTERAÇÃO NO DESENVOLVIMENTO DO PROJETO INTEGRADOR}

Após as reuniões de planejamento e a primeira versão escrita do projeto, a professora Marta comunicou ao grupo que o "projeto foi enviado para o ambiente", e complementou:

Nós temos que construir um cronograma de trabalho, prevendo: trabalho dos grupos em aula, trabalho dos grupos à distância, discussão coletiva sobre texto ou vídeo a respeito de consumir e produzir tecnologias, momento em que entram as demais disciplinas. Para, depois, situar os alunos no cronograma. (Marta, ciberespaço)

A professora disponibilizou no ciberespaço do DPDLiC uma versão inicial, que foi melhorada e novamente postada. Ao comparar as duas versões do projeto foi possível perceber que na primeira se tratava de um esboço escrito pela professora Marta (coordenadora da PEC) e, na segunda versão, os professores das demais disciplinas se inseriram no cronograma de atividades e sugeriram novas bibliografias e atividades para complementar os estudos.

Ao postar a segunda versão, Marta escreveu: "Primeiramente compartilho o processo de constituição do projeto: após reuniões e socialização de ideias por e-mail, chegamos a um documento final envolvendo três disciplinas (Políticas de Gestão e Organização da Educação Nacional, Estrutura de Dados e Informática na Educação)" (Marta, ciberespaço). Houve o desenvolvimento da autonomia docente, pois:

[...] no encontro com os outros (tanto os alunos como as mães e pais, colegas e outros setores sociais), a autonomia ou, caso queira, a emancipação, deveria começar justamente com essa sensibilidade moral, pelo reconhecimento de nossos próprios limites e parcialidades na forma de compreender os outros. Um reconhecimento que não é espontâneo, mas buscado de forma autoexigente e trabalhosa, mas tampouco imposto ou dogmaticamente estabelecido mediante verdades $j a ́$ libertadoras. Vista assim, a autonomia profissional perde seu sentido de autossuficiência para aproximar-se da solidariedade. (Contreras, 2012, p. 206, grifo do original) 
Além do projeto, a professora avisou que compartilhou também "o endereço do site que disponibiliza os Guias de Tecnologias Educacionais, objeto de análise da PEC. http://portal.mec.gov.br/index.php?option=com_content\&view=article\&id= 13018\&Itemid=949" (Marta, ciberespaço). Ao socializar o endereço desse material, proporcionou aos professores que ainda não conhecem o objeto que o fizessem, contribuindo, assim, para ampliar a interação em torno do PI e maximizar a articulação entre os docentes, constituindo um processo de mediação em rede. É nesse sentido que a mediação pedagógica em rede propicia a relação do homem com o meio, contribuindo para a criação de uma "rede semiótica" ou de significação (Pino, 2003, p. 292), que é potencializada na interação, na colaboração e na cooperação realizada entre os sujeitos do grupo.

A professora Marta esclarece que o Guia:

[...] de 2011/2012 é dividido por temas na gestão da educação, ensino e aprendizagem, formação dos profissionais da educação, educação inclusiva, portais educacionais, educação por diversidades - indígenas, jovens e adultos, e educação infantil. Então fornece uma visão bem ampla do que existe catalogado como tecnologias educacionais. O Guia 2011/2012 é bem diferente do 2013 porque ele não está dividido por temas, é um tema só, Guia de Tecnologias Educacionais da Educação Integral e Integrada e da Articulação da Escola com seu Território. (Marta, $1^{\circ}$ encontro presencial, 19 de fevereiro de 2014, p. 19)

Trata-se de um material que provoca a aproximação dos professores/formadores e licenciandos a um aspecto da profissão, a produção de tecnologias educacionais. Entendemos que o contato do licenciando com autores de tecnologias proporciona uma formação acadêmica vinculada com a produção dessas ferramentas, configurando-se como espaço interativo entre licenciandos e profissionais que atuam nessa área, o que prioriza a relação teoria e prática, já que o objetivo do projeto é:

[...] analisar as tecnologias educacionais no que se refere à gestão da educação, ao ensino e aprendizagem, à formação dos profissionais da educação, à educação inclusiva, aos portais educacionais, à educação para a diversidade, campo, indígena e jovens e adultos, educação infantil e educação integral, com vistas a potencializar a construção de softwares nas respectivas áreas. (Projeto Integrador, ciberespaço)

Geralmente, seguimos algumas etapas para o desenvolvimento do projeto integrador: a) apresentação da proposta de estudos aos alunos (temáticas) com problematizações; b) procura, interpretação e seleção de informações; c) estudo e análise dos materiais coletados; d) sistematização dos trabalhos; e e) apresentação do artigo. Esta tem sido nossa principal forma de desenvolvimento das atividades em todos os semestres; ocorrendo modificações conforme a especificidade de cada PI pensado, pois se trata de uma nova turma de alunos com características diferentes; a elaboração do conhecimento é singular, pois cada grupo elabora uma pesquisa que permeia a temática definida para o semestre e que é, posteriormente, socializada no grande grupo. 
Além da redefinição do marco curricular, as opções pedagógicas implicam também na redefinição dos processos de ensino. Esses devem se identificar com ações ou processos de trabalho do sujeito que aprende, pela proposição de desafios, problemas e/ou projetos, desencadeando, por parte do aluno, ações resolutivas, incluídas as de pesquisa e estudos de situações, a elaboração de projetos de intervenção [...]. Isto não se confunde com conferir preeminência às atividades práticas em detrimento da construção dos conceitos. (Ramos, 2012, p. 124)

O PI é marcado pela intencionalidade de que o futuro professor de computação seja um sujeito ativo na produção do conhecimento e que, por meio da utilização de diferentes procedimentos, selecione, interprete e sistematize as informações para contribuir para a construção progressiva da autonomia, sabendo que para isso precisamos criar situações de estudos que articulem o conhecimento de cada campo disciplinar com a realidade, e que os conhecimentos anteriores sejam revistos e postos à prova.

As atividades propostas foram:

Localização do Guia de Tecnologias Educacionais 2011-2012 e 2013 e contextualização dos editais de chamada pública às instituições proponentes; leitura dos documentos; divisão dos grupos por temas e respectiva análise das propostas. Cada aluno deverá analisar uma tecnologia e detalhar como esta foi construída, sob o ponto de vista do desenvolvimento web e da programação; sistematização pelos grupos das propostas; socialização em seminário organizado pelo grupo. (Projeto Integrador, ciberespaço)

Com o projeto definido, a professora Marta comunicou ao grupo que já encaminhou "aos alunos a leitura dos documentos. Estamos analisando os editais de chamada pública do MEC para contextualizar a composição dos referidos guias. Nesta semana os alunos já irão manifestar o interesse pelo tema/pela tecnologia e compor pequenos grupos" (ciberespaço). Com isso demonstra a ocorrência de interlocuções durante o desenvolvimento do projeto, de forma a proporcionar modificações da proposta e solicitar articulações com os demais colegas. Em reunião presencial, a professora Marta solicitou ajuda: "Professora Jussara, eu preciso de ti e do professor João agora, no sentido de em algum momento da aula dar esse suporte para eles [escolher e estudar a tecnologia]. [...] Organizar os grupos e depois fazer toda essa parte de estudar mesmo a tecnologia" (Marta, $1^{\circ}$ encontro presencial, 19 de fevereiro de 2014, p. 22). A professora Jussara respondeu com o que planejou: "Minha ideia é fazer o que? Bom, você apresentou para eles [o Guia], eles vão escolher a tecnologia. Minha ideia é estarmos no laboratório, nos apropriarmos disso pelo site [no site do Guia disponibilizam-se informações sobre a tecnologia, bem como a própria tecnologia]" (Jussara, $1^{\circ}$ encontro presencial, 19 de fevereiro de 2014, p. 22). Isso possibilitou uma análise da tecnologia utilizada para desenvolver o software, bem como uma avaliação da possibilidade ou não de sua utilização na educação.

Nesse processo, notamos algumas dificuldades: os alunos não tomavam a iniciativa de pesquisar e se envolver no projeto, demostravam certa confusão 
diante do desafio de atuarem como protagonistas na produção do conhecimento. Schön (1992, p. 85) afirma que é impossível aprender sem ficar confuso, pois, se não ficar, "jamais poderá reconhecer o problema que necessita de explicação". Para Morin (2015, p. 5), "os modos simplificadores de conhecimento mutilam mais do que exprimem as realidades ou os fenômenos de que tratam". Assim, no lugar de fornecer respostas prontas, o professor ouve e problematiza. Proporciona movimentos de construção do conhecimento, ajudando os discentes a "articular o seu conhecimento-na-ação com o saber escolar” (Schön, 1992, p. 82), o conhecimento tácito com o explícito. Essa transformação do espaço educacional ainda precisa ser construída por professores e alunos, pois no relato percebemos que:

[...] persiste nos sujeitos apenas a visão educacional da via de mão única, verticalizada. Essas questões não podem escapar do debate educacional e necessitam estar em constante problematização num curso de formação de professores, com o intuito de contribuirmos na superação das condições culturais desfavoráveis à escola democrática. (Cambraia, Benvenutti e Moraes, 2016, p. 206)

O PI oportuniza ao acadêmico visualizar a possibilidade de assumir uma postura de autoria, e não simplesmente de assimilação de tecnologias e conteúdos prontos e acabados, importados de fora do ambiente educacional. Para tanto, precisa conhecer todo o processo de constituição de um guia de tecnologias, não focando apenas no produto final. Assim, amplia o papel do professor como um mediador da aprendizagem (Vigotski, 2003), pois esse processo exige um acompanhamento mais personalizado dos trabalhos em andamento para proporcionar a construção de conceitos de cada disciplina. Assim, o futuro professor torna-se um potencial autor de seu próprio material didático, construindo novas formas de interlocução com seus alunos, valorizando um envolvimento interativo para a construção do conhecimento.

$\mathrm{Na}$ interlocução dos professores das diferentes disciplinas, definimos assuntos a pesquisar dentro da temática do semestre, selecionamos, analisamos, interpretamos e sistematizamos as informações. Alguns estudantes escolheram dar continuidade às pesquisas realizadas no semestre anterior, pois, como vimos, as temáticas foram pensadas de forma a constituir uma "espinha dorsal" do curso, proporcionando a continuidade e aprofundando as pesquisas.

Entendemos que ao escrever sobre as temáticas leva-se o professor a interagir com os seus pares, o que consequentemente alavanca novas estratégias de ação e interação, ou seja, discutindo se aprende. Nas palavras de García (1999, p. 21), “a inter-relação entre as pessoas promove contextos de aprendizagem que vão facilitando o complexo desenvolvimento dos indivíduos que formam e que se formam". Com isso, a descrição da atividade realizada foi feita de forma disciplinar na expectativa de possibilitar que nós, os professores, visualizássemos o que os colegas estão propondo, provocando discussões sobre o andamento das atividades e o DPD.

O PI exige um envolvimento comprometido de todos, em todas as etapas do processo de construção do conhecimento, pois gera situações de aprendizagem "reais e diversificadas, e possibilita aos licenciandos decidir, opinar, debater e construir a sua autonomia e seu compromisso com o social, proporcionando a formação 
de sujeitos culturais" (Carneiro, Garrido e Martini, 2012, p. 53-54). O empenho dos alunos é percebido na interação diária em sala de aula e por intermédio das apresentações no SI, que

acontecerá com o objetivo de que cada aluno possa sistematizar suas vivências, durante as práticas do(s) semestre(s). $\mathrm{O}(\mathrm{s})$ seminário(s) acontecerá(ão) de acordo com as possibilidades de seu desenvolvimento durante os semestres, não ficando definido um número exato de quantos acontecerão. (IFFAR, 2014, p. 39)

Assim, o SI é um momento em que os trabalhos desenvolvidos são apresentados, proporcionando interação significativa e reconstrução das práticas/teorias. Por isso, a participação da maioria dos sujeitos envolvidos é fundamental, conforme postagem no ciberespaço da professora Marta, em que grifou as datas do seminário integrador e a importância da participação do coletivo docente, permitindo melhor acompanhamento do projeto:

O terceiro semestre irá sistematizar a escrita da PEC em forma de resumo e socializar em comunicação oral no seminário Integrador. A disciplina de Políticas e Organização da Educação Nacional fará as orientações. O Seminário da PEC do Curso de Licenciatura está agendado para as noites de 3, 4 e 11/07 para as turmas de $5^{\circ}, 3^{\circ}$ e $1^{\circ}$ semestre, respectivamente. É interessante todos os professores do curso organizarem-se para acompanhar e prestigiar os alunos para se inteirarem das propostas das PEC, indiferente de fazerem parte do projeto desse semestre. Nesse sentido, avançaremos no processo de desenvolver as PEC na formação de professores. (Marta, ciberespaço)

É um momento de sistematização e também de problematização, para que se aprofundem os estudos e se abram outras questões de pesquisa para professores formadores e licenciandos. Dessa perspectiva, no SI foi possível potencializar a formação de pesquisadores por meio do ciclo dialético da pesquisa (Moraes e Valderez, 2002). Nesse processo de socialização, além de estreitar os laços entre licenciandos de diferentes semestres, professores formadores e da educação básica, novos horizontes são criados para as pesquisas. Então, o SI faz com que o licenciando retorne para a sala de aula com novos questionamentos, colocando em movimento o motor da pesquisa. Esses espaços de diálogo e pesquisa podem constituir-se:

[...] como ambiente favorável à formação continuada de professores e potencializam desde a formação inicial à constituição de um professor-pesquisador, pois entendemos que pensar, escrever e comunicar uma reflexão proporciona um amadurecimento intelectual de quem comunica e de quem ouve e questiona. (Cambraia, Benvenutti e Moraes, 2016, p. 215)

No SI é possível aperfeiçoar os trabalhos e possibilitar a socialização dessas experiências para impulsionar um educar pela pesquisa. Conforme Cambraia, Benvenutti e Moraes (2016), os trabalhos desenvolvidos alcançaram um nível que proporcionou a participação na V Mostra de Educação Profissional e Tecnológica 
(MEPT) do IFFAR. A socialização dessas experiências com outros pesquisadores é impulsionada pela MEPT, que prioriza a publicação de pesquisas realizadas pelos professores e estudantes.

O DPDLiC proporciona reflexões mais fundamentadas e uma integração curricular na medida em que os professores compartilharam suas concepções, contextos, ideias e dificuldades no desenvolvimento de suas práticas educativas. O processo de relatar, escrever, comunicar e compartilhar essas reflexões proporciona, como explicitado anteriormente, um amadurecimento intelectual dos envolvidos, que se constitui como um desafio para nos constituirmos como intelectuais críticos (Contreras, 2012), autores na docência. O comprometimento em compartilhar reflexões é concretizado na medida em que os professores/formadores do curso se percebem como formadores de professores e se assumem como tal, se envolvem e se responsabilizam pela própria formação e de seus pares, em prol da constituição do futuro professor.

No próximo tópico avaliamos esse processo a partir de um relato discente. Elaboramos uma autoavaliação que traz indícios de como o DPDLiC contribui para a recriação da prática curricular.

\section{AVALIAÇÃO DO PROJETO INTEGRADOR E DESAFIOS AO PROCESSO COLETIVO}

Avaliar o processo desenvolvido por um grupo de professores e alunos de que fazemos parte é desenvolver uma autoavaliação. Estamos todos implicados no processo pedagógico para concretizar o PI. Planejar, desenvolver, avaliar faz parte das atividades docentes e propicia a construção do conhecimento. Assim, a avaliação é processual e formativa: ocorre ao planejarmos e ao desenvolvermos o PI, permitindo repensar e/ou acompanhar as atividades; também ao finalizar o projeto, quando lançamos um olhar retrospectivo ao concretizado.

Com base no relato do PI, percebemos que a recriação da prática curricular foi fundamentada em Lopes (2008), em que cada professor, a partir de seu campo científico e de sua especificidade, dialoga sobre a produção de tecnologias com seus alunos e autores de tecnologias educacionais promovendo uma integração curricular. Trata-se do desenvolvimento de uma integração curricular para romper com a linearidade e fragmentação de disciplinas que, muitas vezes, se apresentam descontextualizadas da realidade escolar e estão pautadas numa lógica da ciência positivista, apenas transferindo para a escola o que é produzido pela ciência (Lopes, 2008). Assim, de acordo com a autora convidada a dialogar, as mudanças na organização curricular dependem de transformações mais profundas nas relações sociais e culturais.

Em 22 de outubro de 2014, no $7^{\circ}$ encontro de estudo coletivo, ao discutir sobre os projetos de trabalho - questionamento da autora do texto estudado, que afirma que o emprego das competências desintegra o currículo -, o professor Gilmar destaca que "não precisamos jogar tudo fora", "o professor vai elencar um conjunto de conteúdos que serão desenvolvidos pelos alunos [temáticas]" (Gilmar, 
$7^{\mathrm{o}}$ encontro presencial, 22 de outubro de 2014, p. 101-102, grifo nosso). Em outras palavras, o professor Gilmar afirma que não entende as competências como um problema, bastando fazer uma inversão, colocando os conteúdos antes das competências. Essa atitude apresenta indícios de um movimento de reflexão crítica do professor diante da recriação da prática curricular.

Nesse sentido, no relato de experiências em análise, afirmamos que o PI "aproxima-se dos projetos de trabalho propostos por Fernando Hérnandez e Monserrat Ventura (1988)" (Cambraia, Benvenutti e Moraes, 2016, p. 205), com o intuito de entender dinâmicas de valorização de conhecimentos anteriores, construção de relações com a realidade e a necessidade do entendimento da cultura discente, criando situações para que sejam sujeitos na construção do conhecimento. Não significa que a organização metodológica dos projetos de trabalho sustenta integralmente o PI. Também não significa que os autores citados no relato fundamentam a integração curricular desenvolvida. Como é salientado no próprio relato: "Fundamentamos essa experiência de integração na PEC em Lopes (2008) [...]. As disciplinas, a partir de seu campo cientifico e sua especificidade, dialogam" (Cambraia, Benvenutti e Moraes, 2016, p. 208), provocando rupturas com a tendência de desenvolvermos uma aplicação imediata e útil ao mercado de trabalho, evitando desenvolver apenas capacidades para efetuar tarefas instrumentais. Em outras palavras, não se trata de valorizar apenas o processo em detrimento do conteúdo.

Ainda nesse relato, também ressaltamos que não tivemos a intenção de adentrar em discussões sobre o currículo integrado, mesmo que no DPDLiC tenhamos realizado com os professores da LC "grupos de estudos sobre o currículo integrado, com o intuito de aprofundar essa temática também na licenciatura" (Cambraia, Benvenutti, Moraes, 2016, p. 200). A distinção ocorre, principalmente, pelos estudos realizados no Ciclos de Estudo sobre Currículo Integrado $(\mathrm{CECI})^{6}$, onde discorremos que a integração curricular fundamentada em Alice Lopes trata de aspectos interdisciplinares, aproximações com a realidade, temáticas, projetos. $\mathrm{O}$ conceito de currículo integrado, com fundamentação em Gaudêncio Frigotto, Marise Ramos, Maria Ciavatta, emerge do "interior do pensamento crítico e marxiano que tematiza a educação a partir de suas interfaces com o mundo do trabalho" (Lottermann e Silva, 2016, p. 17).

De acordo com relato dos professores, "depois de definirmos as reunióes para acompanhar as PEC, notamos uma melhora no trabalho, mas entendemos que ainda precisamos aperfeiçoá-las" (Cambraia, Benvenutti e Moraes, 2016, p. 214). Ao nos referirmos ao aperfeiçoamento, isso significa que ainda depende de um movimento de construção e amadurecimento de práticas/teorias envolvidas nesse processo, para que não fique apenas presente nos documentos. A PEC pode contribuir de forma a impulsionar interações entre educação básica e licenciaturas, promoven-

6 Trata-se de um Ciclo de Estudos sobre o Currículo Integrado, realizado de forma interinstitucional (IFFAR e UNIJUÍ). Para mais informações sobre os estudos realizados no CECI, ver Cambraia e Zanon (2016). 
do uma maior indissociabilidade entre ensino, pesquisa e extensão pelas práticas profissionais, superando a dicotomização entre preparar para as humanidades ou para ciência e tecnologia. Para isso, é necessário ampliar as interações entre os professores, estreitando os laços com a escola e desenvolvendo atividades vinculadas à realidade.

A LC visa a formar o professor de computação, que atua em diferentes espaços relativos à computação e à educação. No primeiro e segundo semestres, os alunos realizam estudos que permitem um olhar para seu campo de trabalho, identificando nas escolas da região possibilidades de articulação e circulação do pensamento computacional. No caso deste projeto em análise, o contato com a realidade não ocorre no espaço da escola, mas com profissionais que desenvolvem tecnologias educacionais, na expectativa de entender como esse processo ocorre e passar a produzir essas tecnologias, bem como questionar, criticar, avaliar, problematizar e refletir sobre tais ferramentas.

O trabalho colaborativo e articulado possibilitou que as disciplinas construíssem e se desafiassem mais na elaboração do conhecimento. Conforme relatado pelos envolvidos no processo:

[...] em semestres anteriores esse tema foi abordado [Políticas públicas de inclusão digital] e não havia tido uma repercussão entre os estudantes. Para alunos de semestres anteriores, o guia de tecnologias é mais um referencial a ser consultado. Até encerrávamos a disciplina lançando o desafio de que poderiam pensar na possibilidade de produzir tecnologias. De forma isolada, porém, a referida disciplina não dava o suporte necessário para a compreensão da construção das referidas tecnologias. (Cambraia, Benvenutti e Moraes, 2016, p. 208)

Os professores destacam a necessidade de uma interlocução para desenvolver uma integração curricular, pois de forma isolada não conseguem ampliar o projeto para além da consulta no Guia. "A integração entre os componentes curriculares ocorreu pela mediação de cada professor na etapa de pesquisa mais correlata ao seu componente curricular" (Cambraia, Benvenutti e Moraes, 2016, p. 210). Com a ajuda dos demais professores, foi possível que o trabalho fosse mais à frente e contemplasse discussões sobre a produção de tecnologias pelas demais disciplinas, significando conceitos de diferentes campos disciplinares, vinculando-os com a realidade.

No relato de Cambraia, Benvenutti e Moraes (2016, p. 202), há um tópico que aborda um relato discente sobre o PI. A intenção foi "compartilhar um olhar por parte de quem participou 'do outro lado' desse processo" e entender se os objetivos do PI estavam sendo alcançados. Foi possível olhar retrospectivamente e "refletir sobre a reflexão na ação. Após a aula o professor e o aluno podem pensar no que aconteceu, [...] no significado que lhe deu e na eventual adoção de outros sentidos" (Schön, 1992, p. 83). Ao fazer uma análise retrospectiva do PI, um aluno que participa do DPDLiC e participou do relato ora analisado, enfatiza: 
Outrora, para a maioria destes educandos, o desenvolvimento de uma TE [Tecnologia Educacional] era algo que poderia ser concebido lançando-se mão dos conhecimentos de caráter estritamente técnico. Contudo, após o estudo do Edital, que dentre os critérios avaliativos das propostas evidencia a "qualidade técnica e pedagógica da proposta" (Brasil, 2010, p. 20), percebemos que a geração de TE é de cunho interdisciplinar e, para que se desenvolva e potencialize a elaboração do conhecimento em sala de aula com essas tecnologias, é necessária a utilização desses conhecimentos na sua criação. (Cambraia, Benvenutti e Moraes, 2016, p. 209)

Assim, o discente percebe o caráter interdisciplinar da LC, sendo que os futuros professores atuarão em diferentes frentes: no ensino da computação, na educação a distância, no desenvolvimento de software educacional e materiais didáticos eletrônicos, no desenvolvimento de projetos, no uso da internet como uma ferramenta cognitiva; e para que ocorra essa interlocução com a educação básica não basta apenas o conhecimento técnico. Ainda demonstra, em seu relato, a apropriação de conceitos estudados no DPDLiC, pois afirma que a atividade desenvolvida na PEC "é um passo à integralidade curricular defendida por Ciavatta [autora estudada no DPDLiC]" [...], e segue trazendo uma citação da autora para explicitar essa integração: "Como formação humana, o que se busca ao adolescente, ao jovem e ao adulto trabalhador é o direito a uma formação completa para uma leitura do mundo e para a atuação como cidadão pertencente a um país, integrado dignamente à sua sociedade política' [novamente, o autor parafraseia Ciavatta]". Esse fator é um indício de como o discente - que participa do DPDLiC e CECI - se apropria do estudo coletivo sobre o currículo integrado para construir significados para sua própria formação.

De acordo com Cambraia, Benvenutti e Moraes (2016), grande parte dos estudantes do curso é composta por trabalhadores; pelo seu cansaço e desgaste físico, nem sempre encontram ânimo e curiosidade para o desenvolvimento das atividades propostas.

No enfrentamento deste problema acreditamos que os professores e alunos precisam estar abertos ao diálogo, a não rigidez instrumental, buscando o incentivo ao aprendizado no sentido de estimular estes educandos a efetuarem o trabalho proposto, prezando e analisando cada etapa caminhada conjuntamente com os discentes, por mais que o resultado final da PEC não seja o outrora idealizado. (Cambraia, Benvenutti e Moraes, 2016, p. 210)

Isso não quer dizer que precisamos abandonar a disciplina e a rigidez do estudo. Talvez, a maior exclusão seja "deixar um aluno passar" sem construir conhecimentos. A rigidez instrumental é a rigidez com que se entende a razão na perspectiva positivista, provocando a "incapacidade para atender todo o processo de atuação que não se proponha à aplicação de regras definidas para alcançar os resultados já previstos" (Contreras, 2012, p. 117); seria o desenvolvimento de tarefas predeterminadas, que desconsideram o imprevisto e a incerteza. Esse pro- 
cedimento, além de não contribuir para a constituição de sujeitos comprometidos com a transformação da sociedade, também não contribui para uma ascensão ao mercado de trabalho. A contextualização e a criação de significados com a compreensão do real como totalidade contribuem para evitar que uma lacuna de conhecimentos se amplie entre os que têm acesso aos bens culturais e os que não têm, e encontra na escola a possibilidade de produção de conhecimentos e cidadania. Trata-se do reconhecimento:

[...] de que a escola unitária deva não apenas democratizar o saber humanístico (público), privilegiando o acesso de todos aos saberes produzidos pela humanidade, como também o reconhecimento de que a escola precisa favorecer no processo de constituição da autonomia dos sujeitos pela via da construção mediata dos conhecimentos. (Lottermann e Silva, 2016, p. 29)

Nesse sentido, conforme relato do aluno, por meio de um diálogo com autores contatados por meio do Guia de Tecnologias, colegas e professores do curso, compreendemos a necessidade de uma integração curricular para a produção de tecnologias educacionais. Também observamos como ocorreu essa integração mediante interdisciplinaridade no curso; percebemos maior envolvimento com essa proposta na disciplina de:

Políticas e Organização da Educação Nacional, que se estendeu além da primeira etapa, com o acompanhamento e mediação em praticamente todas as demais. Além disto, é importante salientar que havia no semestre outros componentes que deveriam ter integrado a PEC [previsto no PPC], porém a aproximação em termos práticos não ocorreu. (Cambraia, Benvenutti e Moraes, 2016, p. 210)

No planejamento, analisado no tópico 1, identificamos o esforço dos professores em pensar e escrever o PI, articulando disciplinas do semestre. Porém, não são todas as disciplinas que conseguem se inserir nas discussões.

Como viemos discutindo sobre o conceito de integração curricular, se contemplar a relação teoria e prática não obrigatoriamente deva contemplar interdisciplinaridade. Se a disciplina não se visualiza no projeto coletivo, devemos forçar uma aproximação? (Marta, ciberespaço)

Entendemos que a interdisciplinaridade forçada é mais prejudicial do que não fazer, pois criar articulações com conteúdos descontextualizados, fragmentados e sem significados acaba prejudicando o processo de constituição da identidade docente. Aproveitar a aproximação com a realidade, proporcionada pelo PI, é uma alternativa para contextualizar e significar os conhecimentos, de criarmos oportunidades para que os estudantes conectem o conhecimento escolar com conhecimentos anteriores e com a realidade. Nessa interlocução, que extrapola o espaço da sala de aula, proporciona-se aos futuros professores entenderem: 
[...] a importância e coerência de, através do movimento de pesquisa, nos formarmos permanentemente, sempre na busca de novos pontos de chegada, onde os caminhos de percurso são tão importantes e significativos quanto os fins. Esse pensamento contribui para uma visão contemporânea de identidade docente, atualizada, conectada, crítica, propositiva. (Cambraia, Benvenutti e Moraes, 2016, p. 212-213)

É pertinente salientar que agimos, no que Schön denomina, de zonas indeterminadas da prática, em que "a incerteza, a singularidade e os conflitos de valor - escapam aos cânones da racionalidade técnica" (Schön, 2000, p.17). $\mathrm{Ou}$, de acordo com uma metáfora apresentada por Schön, entramos em uma “zona pantanosa”, em que o conhecimento não precede à ação, está na ação, é o conhecimento na ação. Para esse autor, o practicum reflexivo refere-se à prática que nos ajuda a aprender as formas de arte que são essenciais para atuar nas zonas indeterminadas da prática. A criação de um practicum reflexivo é um desafio permanente, um processo cíclico, inacabável, que precisa ser cultivado no DPDLiC, para desenvolver a cultura do professor como um sujeito reflexivo, pois “o pensamento complexo também é animado por uma tensão permanente entre a aspiração a um saber não fragmentado, não compartimentado, não redutor, e o reconhecimento do inacabado e da incompletude de qualquer conhecimento" (Morin, 2015, p. 7). Uma formação que não separa o saber do fazer, o pensar do agir, a teoria da prática, visando superar dualidades e constituir o professor como um intelectual crítico (Contreras, 2012).

Nesta investigação enfatizamos que a proposta de organização curricular por meio do PI é relevante para a mobilização de formas mais dinâmicas e significativas de DPD. Foi nesse processo que visualizamos e entendemos como as interações no DPDLiC proporcionaram uma educação outra, pois a formação de professores "deve ser analisada em relação com o desenvolvimento curricular e deve ser concebida como uma estratégia para facilitar a melhoria do ensino" (García, 1999, p. 27), trazendo para a análise as dificuldades, as surpresas e os encaminhamentos sobre o PI.

\section{CONSIDERAÇÕES FINAIS}

O DPDLiC é tratado neste texto como uma tentativa intencional de organizar um processo coletivo de estudo, planejamento e ação entre professores pesquisadores na perspectiva de avançar na direção de romper com a racionalidade técnica, que cria automatismos e fragmentação da formação docente. Diante desse quadro, a ação de pensar em movimentos interdisciplinares se torna algo mecânico e sem significado, prejudicando a constituição da identidade docente. Entendemos que um processo de interlocução docente precisa ser desencadeado para rompermos com a lógica mecanicista e desenvolver professores como intelectuais críticos.

A análise do DPDLiC permite perceber que impulsionamos o desenvolvimento da pesquisa sobre a prática profissional, pois a dinâmica do DPD 
vinculado com a recriação da prática curricular sinaliza indícios de movimentos de mudança que promovem rupturas com o tecnicismo. Em contraposição a ele, compreende-se a formação docente de forma complexa e dialética, realizada na interlocução entre sujeitos com formação e prática diferenciada, que participam e se envolvem ativamente no processo de reconstrução do ensino e da aprendizagem, tornando a pesquisa inerente à prática docente.

Outro aspecto a destacar refere-se à dinamicidade do espaço interativo coletivamente vivenciado, assumido como de importância fundamental ao avanço da formação ao longo da investigação. Isso é atribuído ao fato de o DPDLiC ter contemplado interações presenciais e no ciberespaço - potencializando, cada vez mais, intersubjetividades que iam proporcionando o DPD na recriação da prática curricular e contribuindo, dessa forma, para saber lidar com resistências decorrentes dos descompassos entre disciplinas da área pedagógica e das ciências humanas e as disciplinas de formação técnica. Para além de transmitir informações e mensagens, o compartilhamento das ações proporcionou a contextualização do PI compreendendo o real como totalidade. Nessa interlocução docente ocorreu maior autonomia na produção curricular, em que uns ajudam os outros a pensar ações que possibilitem a constituição docente. Nesse sentido, a autonomia, proporcionada no DPDLiC, tem mais a ver com a solidariedade do que com autossuficiência.

Dessa forma, durante o planejamento e desenvolvimento do PI observamos maior interlocução entre docentes, que requisitavam ajuda dos colegas para desenvolverem as atividades vinculadas com o mundo do trabalho, problematizando o conhecimento e impulsionando um maior protagonismo aos futuros professores. Com essa dinâmica, foram potencializadas mediações em rede, em que cada docente se responsabilizou pela formação de seu colega e dos futuros professores. Esses fatores são indícios do DPD com integração curricular, constituindo novos conhecimentos que de forma fragmentada não seriam construídos.

Além da interdisciplinaridade proporcionada pelo PI, esse processo potencializou um educar pela pesquisa, pois, ao organizarmos o SI para sistematizar os estudos, proporcionamos aos envolvidos no processo um momento de comunicação dos argumentos construídos. Essa socialização produziu novos questionamentos e um recomeço do ciclo dialético da pesquisa. Com isso, os professores/formadores junto com os licenciandos desenvolveram um olhar crítico ao PI, refazendo-o permanentemente. Não há acomodação na atividade proposta. Assim, cada semestre é um novo projeto. Isso é permitido com o comprometimento dos professores do curso ao se perceberem professores/formadores. Diante disso, entendemos que sem um movimento formativo vivenciado no DPDLiC a integração fica somente na intenção.

Por fim, deixamos um desafio aos cursos de licenciatura: como levar cada grupo a instituir a pesquisa-ação? Desejamos que este texto sirva como motivação para que esse processo de estudo coletivo seja vivenciado no interior de cada novo grupo. Assim, neste texto se encontra um motivo forte para a criação de grupos de pesquisa-ação crítica e emancipatória para o DPD como perspectiva para a recriação permanente da formação e da prática curricular. 


\section{REFERÊNCIAS}

Bazzo, W. A. Ciência, Tecnologia e Sociedade: e o contexto da educação tecnológica. 3. ed. Florianópolis: Ed. da UFSC, 2011.

Cafezeiro, I.; Costa, L. C. DA; Kubrusly, R. Modos contemporâneos de aprendizado e construção do conhecimento: reflexões sobre o ensino de Teoria da Computação para Sistemas de Informação. In: Congresso da Sociedade Brasileira de Computação, 35., 2016, Porto Alegre. Anais... Porto Alegre: 04 a 07 de julho de 2016. In: Wor kshop sobre Educação em Computação. Computação e Interdisciplinaridade, 24., 2016, Porto Alegre: 04 a 07 de julho de 2016.

Cambraia, A. C.; Bender, L. Desenvolvimento Profissional Docente na Licenciatura em Computação: espirais reflexivas para o desenvolvimento das Práticas como Componente Curricular. In: Cambraia, A. C.; Rosmann, M. A.; Soares, R. C. Prática Profissional na Educação Tecnológica: concepções, experiências e dinâmicas investigativas. Passo Fundo: Ed. Méritos, 2015. p. 41-50.

.; Benvenutti, L.; Moraes, M. G. O Projeto Integrador num Curso de Licenciatura: a reconstrução de saberes através do movimento dialógico. In: Hames, C.; Zanon, L.; Pansera-DE-Araújo, M. C. Currículo Integrado, Educação e Trabalho: saberes e fazeres em interlocução. Ijuí: Ed. UNIJUÍ, 2016. p. 199-220.

.; ZanON, L. Explorando o território do desenvolvimento profissional docente: notas a partir de uma revisão com foco nas licenciaturas. Revista de la Faculdad de Ciencia y Tecnologia, Universidad Pedagogica Nacional, v. 1, p. 732-738, 2016.

. Interlocuções de saberes na pesquisa-ação mediada por estudos sobre a temática pertinente ao currículo integrado. In: HAMMES, C.; ZANON, L. B.; PANSERADE-ARAÚJO, M. C. Currículo Integrado, Educação e Trabalho: saberes e fazeres em interlocução. Ijuí: Editora UNIJUÍ, 2016. p. 57-89.

Carneiro, E. B. B.; Garrido, L. H.; Martini, V.P. Ensino de Química: aprendizagem ativa na formação docente. In: Goes, G. T.; Снамма, O. T. Arquitetura da prática: interação do saber-fazer nas licenciaturas. Ponta Grossa: Editora UEPG, 2012.p. 47-62. Carr, W.; Kemmis, S. Teoría crítica de la enseñanza: investigación-acción en la formación del profesorado. Barcelona: Martinez Roca, 1988.

Contreras, J. A autonomia de professores. Traduzido por: Sandra Trabucco Valenzuela. 2. ed. São Paulo: Cortez, 2012.

Fiorentini, D.; Crecci, V. M. Desenvolvimento Profissional Docente: um termo guarda-chuva ou um novo sentido à formação? Revista Brasileira de Pesquisa sobre Formação de Professores, v.5, n.8, jan./jun., 2013.

García, C. M. Formação de professores: para uma mudança educativa. Porto - Portugal: Porto Editora, LDA, 1999.

Góes, M. C. R. de. A abordagem microgenética na matriz histórico-cultural: uma perspectiva para o estudo da constituição da subjetividade. Cadernos Cedes, v. 20, n. 50, p. 9-25, abr. 2000. 
Hames, C.; Zanon, L.; Pansera-de-Araújo, M. C. Currículo Integrado, Educação e Trabalho: saberes e fazeres em interlocução. Ijuí: Ed. UNIJUÍ, 2016.

Instituto Federal de Educação, Ciência e Tecnologia Farroupilha (IFFAR). Projeto Pedagógico do Curso de Licenciatura em Computação. Instituto Federal Farroupilha, Campus de Santo Augusto, 2012. Disponível em: <http://www.sa.IF Farroupilha.edu.br/>. Acesso em: 29 mar. 2014.

Imbernón, F. A formação continuada de professores. Porto Alegre: Artmed, 2010.

LÉvy, P. Árvores de Saúde: uma conversa com Pierre Lévy. Entrevista realizada em 31 de maio de 1998. Revista interface - Comunicação, Saúde e Educação, p.143-156, fev. 1999. Disponível em: <http://www.scielo.br/pdf/icse/v3n4/12.pdf. >. Acesso em:11 nov. 2016. LibÂneo, J. C. Formação de professores e didática para o desenvolvimento humano. Revista Educação e Realidade, Porto Alegre, v. 40, n. 2, p. 629-650, abr.-jun. 2015.

Lopes, A. C. Políticas de integração curricular. Rio de Janeiro: EdUERJ, 2008.

Lottermann, O.; Hames, C.; Rosmann, M. A. Currículo Integrado na Educação Profissional de Nível Médio: o curso técnico em Agropecuária no Instituto Federal Farroupilha.In: Hames, C.; Zanon, L.; Pansera-DE-Araújo, M. C. Currículo Integrado, Educação e Trabalho: saberes e fazeres em interlocução. Ijuí: Ed.UNIJUI, 2016. p. 91-106.

; Silva, S. P. da. A gênese o currículo integrado: referenciais teóricos e suas implicações políticas, epistemológicas e sociais. In: Hames, C.; Zanon, L.; PANSERA-DEAraújo, M. C. Currículo Integrado, Educação e Trabalho: saberes e fazeres em interlocução. Ijuí: Ed. UNIJUÍ, 2016. p. 17-36.

Lüdke, M.; AndrÉ, M. E. A. Pesquisa em Educação: abordagens qualitativas. São Paulo: EPU, 1986.

Moraes, R.; Valderez, M. do R. L. (Orgs.). Pesquisa em sala de aula: tendências para educação em novos tempos. Porto Alegre: EDIPUCRS, 2002.

Morin, E. A cabeça bem-feita: repensar a reforma, reformar o pensamento. Traduzido por: Eloá Jacobina. 12. ed. Rio de Janeiro: Bertrand Brasil, 2006.

. Os sete saberes necessários à educação do futuro. Traduzido por: Catarina E. F. da Silva e Jeanne Sawaya. 2. ed. Revisada. 3 reimp. São Paulo: Cortez; Brasília, DF: UNESCO, 2011.

. Introdução ao pensamento complexo. Traduzido por Eliane Lisboa. 5. ed. Porto Alegre: Sulina, 2015.

Pino, A.Técnica e Semiótica na Era da Informática. Contrapontos, v. 3, n. 2, maio-ago., Itajaí, 2003.

Ramos, M. Possibilidades e desafios na organização do currículo integrado. In: Frigotto, G.; Ciavatta, M.; Ramos, M. (Orgs.). Ensino Médio Integrado: concepção e contradições. 3. ed. São Paulo: Cortes, 2012. p. 107-128.

Schnetzler, R. P. O professor de Ciências: problemas e tendências de sua formação. In: .; Aragão, R. P. M. (Org.). Ensino de Ciências: fundamentos e abordagens.

CAPES/UNIMEP, 2000. p. 13-25. 
SснӧN, D. A Formar professores como profissionais reflexivos. In: NÓVOA, A. (Org.). Os professores e sua formação. Lisboa: Dom Quixote, 1992.

.Educando o Profissional Reflexivo: um novo design para o ensino e aprendizagem. Traduzido por: Roberto Cataldo Costa. Porto Alegre: Artmed Editora, 2000.

Shulman, L. Those who understand: knowledge growth in teaching. Educational, v. 15, n. 2, p. 4-14, 1986.

VIGotski, L. S. A formação social da mente: o desenvolvimento dos processos psicológicos superiores. Traduzido por: José Cipolla Neto; Luís Silveira Menna Barreto; Solange Castro Afeche. 6. ed. São Paulo: Martins Fontes, 2003.

\section{SOBRE OS AUTORES}

Adão Caron Cambraia é doutor em educação nas ciências pela Universidade Regional do Noroeste do Estado do Rio Grande do Sul (UNIJUÍ). Professor do Instituto Federal de Educação, Ciência e Tecnologia Farroupilha (IFSul).

E-mail: adao.cambraia@iffarroupilha.edu.br

Lenir Basso Zanon é doutora em educação pela Universidade Metodista de Piracicaba (UNIMEP). Professora da Universidade Regional do Noroeste do Estado do Rio Grande do Sul (UNIJUÍ).

E-mail: bzanon@unijui.edu.br

Recebido em 8 de julho de 2017 Aprovado em 24 de novembro de 2017 